\title{
Design and Implementation of an Open Source G.I.S. Platform For Management of Anthropological Data
}

\author{
S. Gugnali ${ }^{1}$, L. Mandolesi ${ }^{2}$, V. Drudi ${ }^{1}$, A. Miulli ${ }^{1}$, M.G. Maioli ${ }^{3}$, M.A. Frelat ${ }^{1}$, G. Gruppioni ${ }^{1}$ \\ ${ }^{1}$ Università di Bologna. Dipartimento di Storia e Metodi per la Conservazione dei Beni Culturali (University of Bologna. \\ Department of History and Conservation Methods for Cultural Resources): Via degli Ariani, 1, 48121 Ravenna, Italy. \\ E-mail: giorgio.gruppioni@unibo.it \\ 2 adArte di Luca Mandolesi \& Co. s.n.c., Rimini, Italy \\ ${ }^{3}$ Soprintendenza per i Beni Archeologici dell'Emilia-Romagna, Bologna, Italy
}

KEYWORDS: G.I.S. platform, Free Open-Source Software, paleodemography, late antiquity/middle age, Rimini (Italy).

\section{Introduction}

The need to computerise the archaeoanthropological data from excavation sites and laboratory study has intensified the development of technological applications for archaeology (Mandolesi, 2009; Coschino et al., 2011). Hence the idea of pyArchlnit (https://sites.google.com/ site/pyarchinit/), a plug-in written in Python for Qgis, a Free Open Source Software (FOSS) for spatial data management created by Mandolesi (2009), initially formulated for the management of excavation data and then expanded to other areas relating to archaeology and cultural resources. It is inspired by the concept of FOSS that can be customised as far as possible, i.e. modified according to any requirements. This software is able to manage alphanumeric, topographic and multimedia data simultaneously, so as to build database that are usable and accessible by all, the ultimate goal being the display of results on a Geographic Information System (G.I.S.) platform.

This kind of system seeks to facilitate and complement the study of burial sites during excavation and laboratory study. The software aims to meet the need to display and compare a large quantity of data at the same time, to make research faster and more precise, for the purpose of sharing it widely. In order to complete the study of human remains from archaeological sites by means of laboratory analysis, it is essential for the data to be recorded simply, quickly and effectively. The resulting system can thus provide an overview of both the necropolis in question and all the other necropolises eventually recorded on the platform. It is therefore possible to interrogate the software in order to produce statistics that allow the data both within sites and between different sites to be crossreferenced and displayed. The aim of the present work was to develop the above software with a database section for anthropological data. Three model datasheets (Fig. 1 to 3) for each individual. A series of unique identifiers linking the individual record to the geo-referenced map were used to create the interrelationships between the various datasheets, and this information was integrated with the database.

\section{Materials and Methods}

Starting from the premise that the mechanisms used had to be in line with the main features of Open Source programs (high scalability on the main operating systems, simplicity, clarity and complete availability to users), the choice fell on the following software: Qgis/GRASS for the G.I.S., Python for the programming language, PostgreSQL for the database, and Inkscape for the print layout.

The first step was the creation of a datasheet to summarise the basic features of each individual examined, called Individual Datasheet (Fig. 1). In addition to the

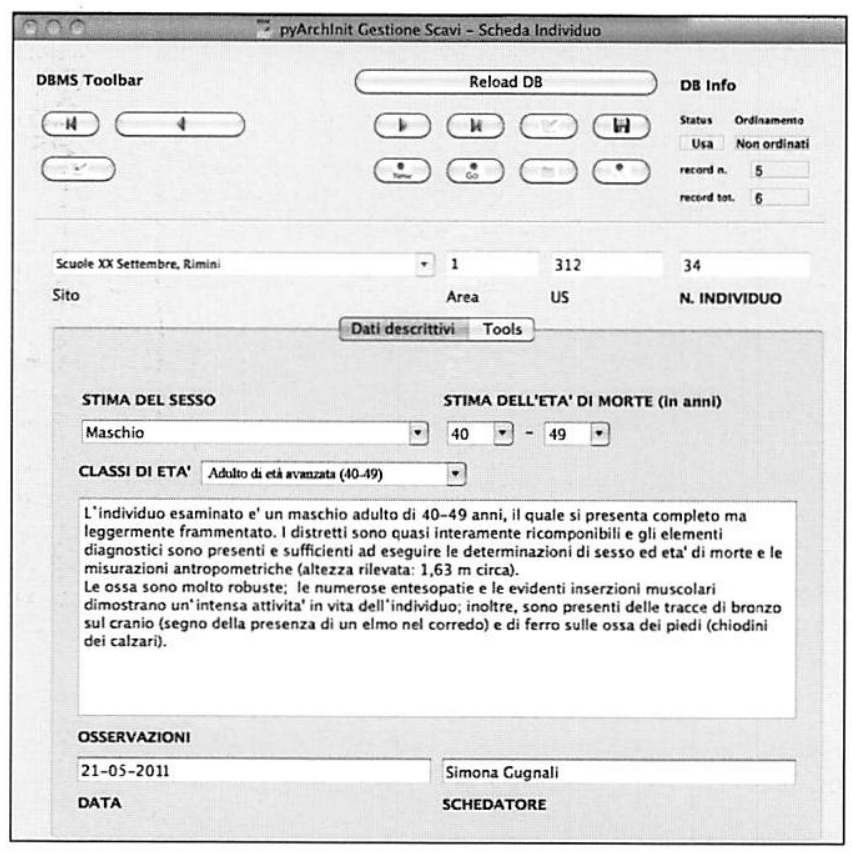

Fig. 1. Example of a filled Individual Datasheet. 
excavation data, it synthesises the anthropological data recorded into two datasheets containing the analytical methods of sex and age determinations in adults: the Sex Determination Datasheet (Fig. 2) and the Age-at-death Estimation Datasheet (Fig. 3). Sex was determined by

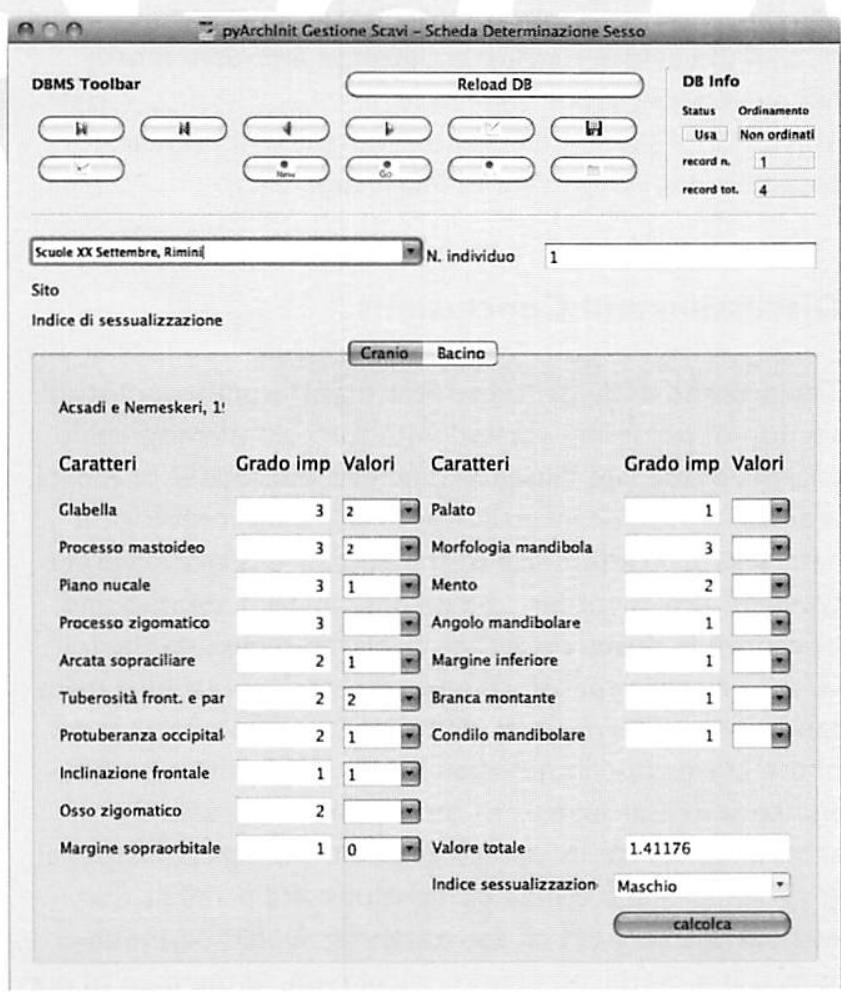

Fig. 2. Screenshot of the Sex Determination Datasheet.

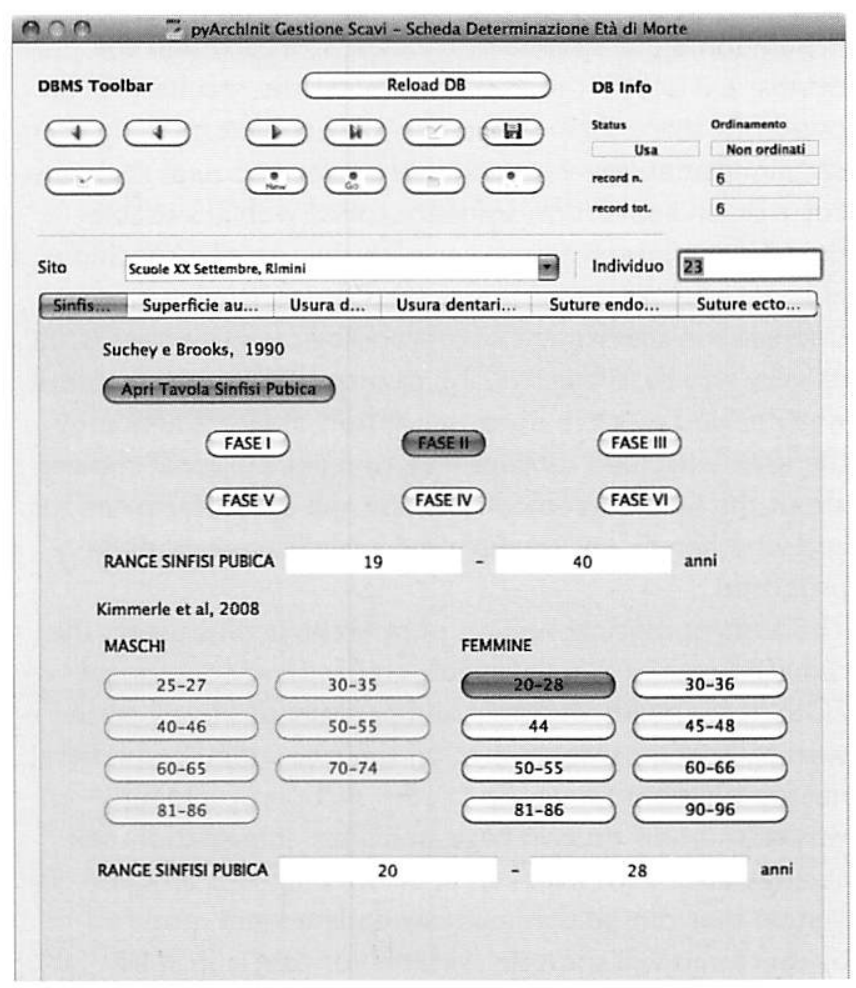

Fig. 3. Screenshot of the Age-at-death Estimation Datasheet.

observing the morphology of the pelvis (Bruzek, 2002), and of the skull (Acsadi and Nemeskeri, 1970) when the former was not preserved.Age-at-death was assessed on the basis of changes in the pubic symphysis (Brooks and Suchey, 1990; Kimmerle et al., 2008) or the auricular surface of the ilium (Schmitt, 2005), and when the pelvis was not preserved, using tooth wear (Lovejoy, 1985) or the obliteration of the ectocranial (Meindl and Lovejoy, 1985) and endocranial sutures (Acsadi and Nemeskeri, 1970). Subadult age-at-death was estimated from dental eruption (Ubelaker, 1978), measurement of long bone length (Maresh, 1970), and degree of ossification and skeletal development (Scheuer and Black, 2000).

To test the effectiveness of the plug-in and try out the anthropological section of pyArchlnit, we studied the remains from the late antiquity/medieval necropolis from Rimini, in Via A. da Brescia (Maioli, 2009; Miulli et al., this volume).

\section{Results}

The osteological examinations revealed that the 61 burials under study are those of 28 adults and 35 subadults. Of the 28 adult individuals, 14 are males (50\%), 9 are females $(32 \%)$ and 5 remain indeterminate $(18 \%)$ due to the very poor condition of the skeletal remains. The sex distribution of the population sample is unbalanced with a sex-ratio equal to 1.5 , but in the eventuality that all the indeterminate specimens would all be female, the sexratio would fall to equilibrium. However this possibility is very unlikely. The demographic profile by age group (Fig. 4) shows that $69 \%$ of the subadults are children under the age of 10 . Compared to the normal mortality profile

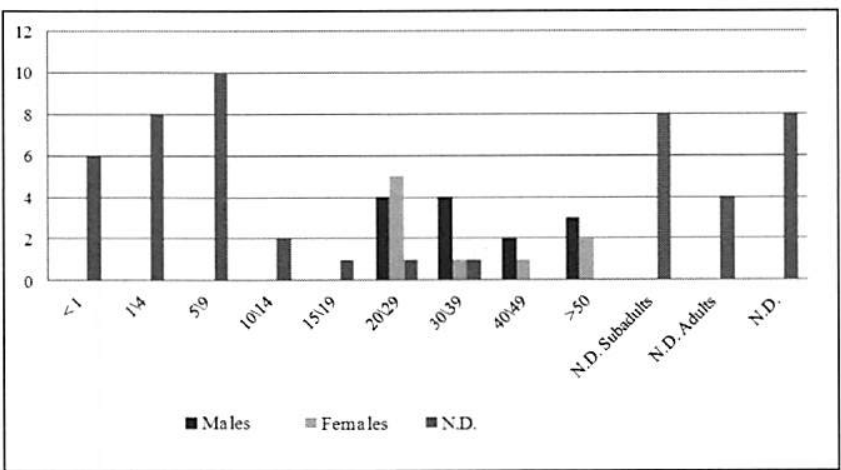

Fig. 4. Age and sex distribution of the sample from the late antiquityl medieval necropolis from Rimini (Via A. da Brescia).

(Ledermann, 1969), the number of infants dying within the first year of life appears very low, but it seems plausible to attribute this to the fact that the remains of small infants are not so easily preserved or that they are buried elsewhere. In total, only $46 \%$ of the population sampled reached adulthood and a third of them died by the age of $30.55 \%$ of females died between 20 and 29 years old, during the period of higher fertility, while the majority of males distribute themselves equally among the age groups 20-29 and 30-39.

The data resulting from the paleodemographic analysis, summarized in the Individual Datasheet, were entered on the new database and displayed on a G.I.S. platform (Fig. 5). Cross 


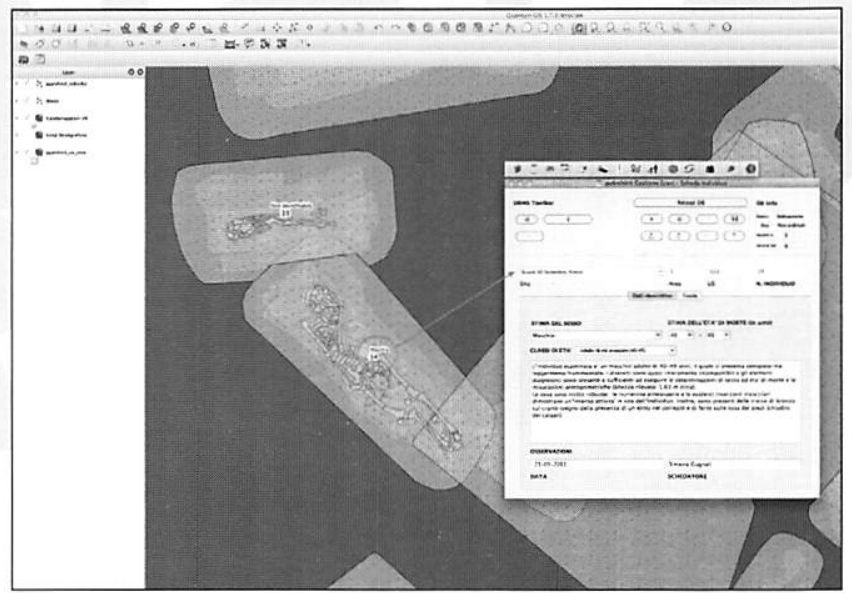

Fig. 5. Screenshot of Individual Data Display associated with Burial 34 in the geo-referenced late antiquity/medieval necropolis from Rimini (Via A. da Brescia).

analyses can then be carried out using the G.I.S. functions. It is thus possible to enable or disable the "G.I.S. mode", during which any research carried out on the interface is converted into a composite plan in QGIS. The maps showing the burial distribution according to sex and age-at-death are presented in Fig. 6 and Fig. 7, respectively. No particular burials cluster

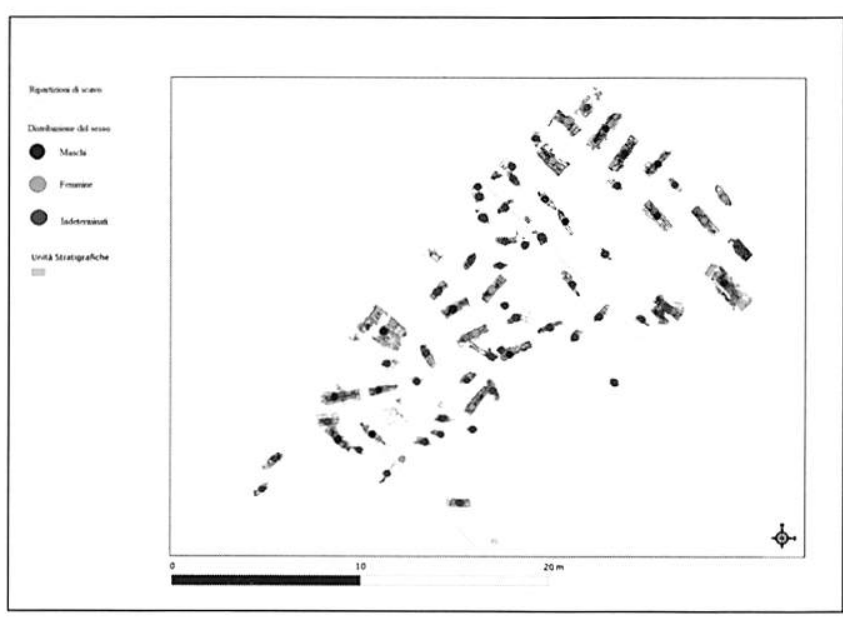

Fig. 6. Spatial distribution according to sex of the burials from the late antiquity/medieval necropolis from Rimini (Via A. da Brescia).

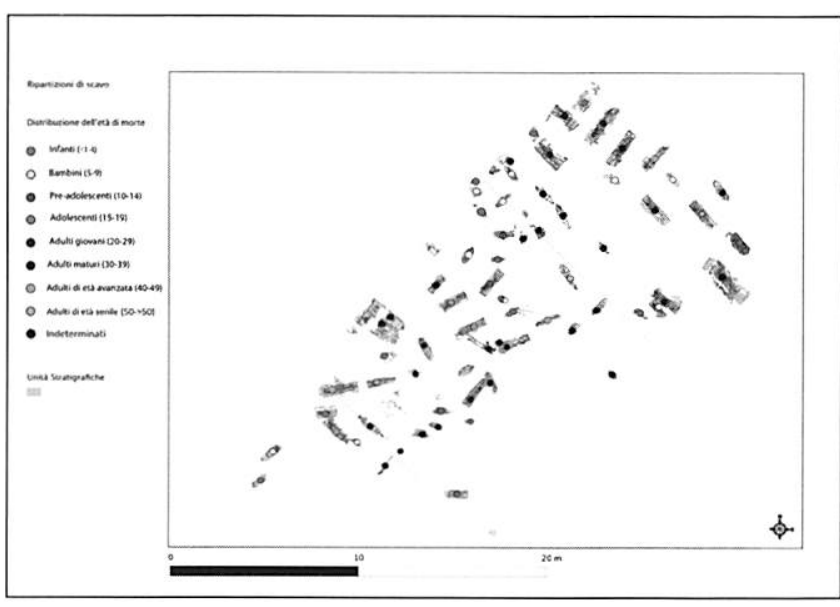

Fig. 7. Spatial distribution according to age-at-death of the burials from

the late antiquity/medieval necropolis from Rimini (Via A. da Brescia). are evidenced on either of the maps. The eventual groups observed need to be considered in relation to the fact that the necropolis covers a rather wide span $\left(4^{\text {th }}-9^{\text {th }} \mathrm{C}\right.$. A.D.) and may thus result from the accumulation of burial periods. It is interesting to note that, from the area examined (although it does not represent the whole necropolis), about $50 \%$ of the human remains are juvenile and were mostly discovered lying inside amphorae.

This could suggest a differential mortuary treatment for subadults and a high rate of infant mortality.

\section{Discussion and Conclusions}

The present study demonstrates that the anthropological section of pyArchlnit, tested with the paleodemographic analysis of the late antiquity/medieval necropolis of Rimini, is a useful tool for investigating archaeoanthropological data. The main advantage of this software is that different types of data, that may come from different sources and be stored in PostgreSQL, are displayed thanks to the G.I.S. in a single spatial analysis project. The resulting maps can be then interrogated without limits. The observation of the graves distribution can bring to light the cultural and sociological aspects of the populations studied according to various criteria (e.g., chronological, historical, geographical) and create correlations and parallels that, without the support of the computer, would be, if not impossible, quite complex to implement. In the case of our paleodemographic analysis, no particular burials cluster are evidenced, according to neither gender nor age-at-death, as expected for a late antiquity/early medieval necropolis. In addition, since all type of data are stored within the database, it allows the user to process the results with an option to share them into a network, so that multiple users can simultaneously view and share information in real time. For that, an application software called webGIS, usable through the internet browser with the use of a specific plug-in or by means of separate software, is necessary. Because the assessment of morphological characters is, by its very nature, subjective and cannot be fully automated, it was decided to leave open the option of direct action by the user, who then remains free to make personal choices about the final outcome in the sex and age determinations, and whether or not to apply the analytical methods proposed.

The anthropological section of pyArchlnit thus meets the requirements of a user-friendly archaeoanthropological FOSS. It is already designed and partially positively tested with paleodemographic data on the late antiquity/medieval necropolis from Rimini. So far, the section developed was tested only on two basic individual information: sex and age-at-death. However, since the plug-in is an open system that can be continuously updated and modified by users and will soon be available for use, it shall be easy for anyone to improve and develop the system, therefore quickly offering an operational framework to the anthropological community. Indeed as its structure keeps separate all aspects of the project, any users could not only edit the code at will but also the whole package of a single 
section, so as to offer a rapid and neat analysis management system.

Further implementations using additional type of data (e.g., morphological, anthropometric, paleopathological and paleonutritional data) derived from anthropological analyses on both adult and subadult individuals, whether buried, cremated or mummified, will be necessary to cover all fields of archaeoanthropology, in order to create a database that can be used, consulted and corrected quickly and easily by all the academics.

\section{Acknowledgements}

The authors wish to thank Dr. Renata Curina from the "Soprintendenza per i Beni Archeologici" (Department of Archaeological Resources) of Emilia-Romagna (Italy) who granted us the honour of studying the human remains in her custody.

\section{References}

Acsadi G., Nemeskeri J. 1970. History of Human Life Span and Mortality,Akadémiai, Budapest.

Brooks S., Suchey J.M. 1990. Skeletal age determination based on the os pubis: a comparison of the Acsádi-Nemeskéri and Suchey-Brooks methods, Hum. Evol., 5: 227-238.

Bruzek J. 2002.A Method for visual determination of sex in human hip bone.Am.J. Phys. Anthrop., 117: 157-168.

Coschino F., Fornaciari A., Minozzi S. 2011. Computer models and applications for the management of anthropological data.J. Anthropol. Sci., 89: 195-199.
Kimmerle E.H., Konisberg L.W., Jantz R.L., Baraybar J.P. 2008. Analysis of age of death estimation through the use of pubic symphyseal data. J. Forensic Sci., 53: 558-568.

Ledermann S. 1969. Nouvelles tables-types de mortolité, INED, Paris.

Lovejoy C.O. 1985. Dental wear in the Libben population: Its functional pattern and role in the determination of adult skeletal age at death. Am.J. Phys. Anthrop., 68:47-56.

Maioli M.G. 2009. Relazione di scavo: Comune di Rimini, Scuole XX Settembre - via Arnaldo da Brescia. Direzione scientifica per la Soprintendenza ai Beni Archeologici dell'Emilia-Romagna.

Mandolesi L. 2009. pyArchlnit - Python, Qgis e PostgreSQL per la gestione dei dati di scavo. In: Cignoni P., Palombini A., Pescarin S. (eds), ARCHEOFOSS Open Source, Free Software e Open Format nei processi di ricerca archeologica,Atti del IVWorkshop (Roma, 27-28 aprile 2009), «Archeologia e Calcolatori supplemento 2 - 2009», Edizioni All'Insegna del Giglio, Firenze,. https://sites.google.com/site/pyarchinit/: 209-222.

Maresh M.M. 1970. Measurements from roentgenograms. In: McCammon R.W. (eds.), Human Growth and Development. Springfield, IL: C.C.Thomas:157-200.

Meindl R.S., Lovejoy C.O. 1985. Ectocranial suture closure:A revised method for determination of age at death based on lateral anterior suture. Am.J. Phys. Anthrop., 68: 57-66.

Miulli A., Drudi V., Gugnali S., Guidi E., Frelat M.A.,Andretta M., Gruppioni G. (2011). Archaeoanthropological study of the necropolis on Via A. da Brescia - Rimini (4 ${ }^{\text {th }} 9^{\text {th }}$ C.A.D.). J. Biol. Res, 84: 252-253..

Scheuer L., Black S. 2000. Developmental Juvenile Osteology, Academic Press.

Schmitt A. 2005. Une nouvelle méthode pour estimer l'âge au décès des adultes à partir de la surface sacro-pelvienne iliaque. Bull. Mém. Soc. Anthropol. Paris, 17: 89-101.

Ubelaker D.H. 1978. Human Skeletal Remains: Excavation, Analysis, Interpretation. Washington, DC: Smithsonian Institute Press. 